\title{
Giardia duodenalis: New Research Developments in Pathophysiology, Pathogenesis, and Virulence Factors
}

\author{
Andre G. Buret ${ }^{1,2} \cdot$ Christina B. Amat $^{1} \cdot$ Anna Manko $^{1} \cdot$ Jennifer K. Beatty $^{1}$. \\ Marie C. M. Halliez ${ }^{1}$ - Amol Bhargava ${ }^{1}$ - Jean-Paul Motta ${ }^{1}$. James A. Cotton ${ }^{1}$
}

Published online: 11 July 2015

(C) Springer International Publishing AG 2015

\begin{abstract}
Giardia duodenalis is a very common, ubiquitous, intestinal protozoan parasite infecting animals and humans. Of the eight distinct genetic assemblages known to date, assemblages A and B are infectious to humans. Giardia is the most commonly recognized cause of traveller's diarrhea. Giardiasis impairs weight gain and is responsible for a variety of extraintestinal and post-infectious complications, including postinfectious irritable bowel syndrome, chronic fatigue, failure to thrive, and cognitive impairment. Giardiasis occurs in the absence of invasion of the intestinal tissues by the trophozoites and in the absence of any overt inflammatory cell infiltration, with the exception of a modest increase in intraepithelial lymphocytes and mast cells. In endemic parts of the World where the infection is often concurrent with bacterial enteritis causing inflammation-driven diarrheal disease, giardiasis appears to be protective against diarrhea. Recent observations have demonstrated that this effect may be due to a direct immuno-modulating effect of the parasite via its cathepsin B cysteine protease which cleaves pro-inflammatory CXCL8. No known toxin has yet been directly implicated in the pathophysiology of giardiasis. Diarrhea in giardiasis is mostly malabsorptive in nature, rather than hypersecretory. Findings from ongoing research indicate that the post-infectious effects
\end{abstract}

This article is part of the Topical Collection on Protozoa (Giardia)

Andre G. Buret

aburet@ucalgary.ca

1 Biological Sciences, Host-Parasite Interactions Network, Inflammation Research Network, University of Calgary (AB), Calgary, AB, Canada

2 Biosciences, University of Calgary, 2500 University Dr. N.W., Calgary, AB T2N 1N4, Canada of giardiasis may be due to microbiota dysbiosis induced by the parasite during the acute phase of infection.

Keywords Giardia $\cdot$ Pathogenesis $\cdot$ Immuno-modulation · Microbiota $\cdot$ Post-infectious $\cdot$ Pathophysiology

\section{Introduction}

Giardiasis is caused by the diplomonad protozoan Giardia duodenalis (synonymous Giardia lamblia or Giardia intestinalis). It is the most common waterborne parasitic infection of the human intestine worldwide. Due to the high burden of $G$. duodenalis-related illnesses in the developing world, its impairment on development and socioeconomic improvements, and its close association with poverty, this parasite has been included in the World Health Organization's (WHO) Neglected Diseases Initiative since $2006[1 \bullet, 2,3 \bullet \bullet$. $G$. duodenalis is the most commonly recognized etiologic agent of traveller's diarrhea [4]. Eight distinct genetic assemblages, "A" through "H," are known to exist for G. duodenalis thus far. Assemblages A and B are infectious to humans, while assemblage $\mathrm{E}$ is thought to exhibit a predilection for livestock $[3 \bullet \bullet, 5,6]$. The anthropo-zoonotic potential of the parasite has been well established [7-12]. Giardiasis may significantly impair productivity in food-producing animals [13-15]. $G$ duodenalis has a simple life cycle, which includes the dormant infective cyst released in the feces, each producing, upon exposure to gastric juices during ingestion, one tetranucleated short-lived excyzoite, which will divide twice to give rise to four diploid trophozoites [3••]. Trophozoites are the diseasecausing stage and colonize the upper small intestine, where they adhere to the epithelial surface and proliferate by binary fission. Pathophysiology in the acute phase of giardiasis occurs in the absence of invasion of the intestinal tissues by the 
trophozoites and in the absence of any overt inflammatory cell infiltration, with the exception of a modest increase in intraepithelial lymphocytes and mast cells $[16,17 \cdot]$. No known toxin has yet been unequivocally implicated in the pathophysiology of giardiasis $[3 \bullet \cdot, 16]$. Clinical manifestations of giardiasis usually appear 1 to 2 weeks after infection and may range from asymptomatic to acute or chronic diarrhea, abdominal pain, vomiting, and weight loss $[3 \bullet \bullet, 13,14$, $16,18,19 \cdot \bullet$. Recent evidence indicates that $G$ duodenalis, like other enteropathogens, may cause chronic postinfectious complications, including irritable bowel syndrome, via mechanisms that remain obscure $[20 \bullet, 21 \bullet, 22 \bullet \bullet, 23,24]$. Similar to most infectious diseases, a variety of host and environmental factors modulate disease outcome in giardiasis. They include diet, immune factors, age, and concurrent infections $[3 \bullet \bullet, 16,22 \bullet \bullet, 25 \bullet, 26,27,28 \bullet, 29 \bullet \bullet, 30,31]$. In view of the importance of Giardia in the context of water- and foodborne illnesses around the Globe, and in the light of the increasing frequency of food-borne disease in today's society [32], a better understanding of the biology and pathogenesis of this parasite is sorely needed. This review provides an update of the most recent research advances on the mechanisms regulating disease in giardiasis.

\section{Intestinal Pathophysiology in Giardiasis}

Each year, G. duodenalis infects over 280 million individuals, of which 20,000 cases are reported in the USA alone [3••, 33]. The highest prevalence of giardiasis is observed in developing countries, where it may range from 20 to $100 \%$ of the population $[3 \cdot \bullet, 16]$. In contrast, prevalence rates of giardiasis in developed countries may vary between 3 and $10 \%$ [34]. A classic study has established Koch's postulate for G. duodenalis and demonstrated that this protozoan parasite is a true pathogen [35]. Yet, people infected with G. duodenalis develop a broad range of clinical manifestations, ranging from an absence of symptoms to acute or chronic diarrheal disease with abdominal pain and nausea $[3 \bullet \bullet, 16,18]$. Diarrheal symptoms mostly occur during the acute phase of the infection. The majority of Giardia infections are self-limiting, although reinfection and chronic infection can occur. Although at least some of the effects of the infection are isolate-dependent, the biological basis of this broad range of clinical presentations in giardiasis remains incompletely understood. Research over the past two decades has established that the pathophysiology of giardiasis is multifactorial and involves parasitic, host, dietary, and environmental factors, as well as immunological and non-immunological processes $[3 \bullet \bullet, 16]$.

The pathophysiology of acute diarrhea in giardiasis implicates increased rates of enterocyte apoptosis, a disruption of the intestinal barrier function, activation of host lymphocytes, CD8+ lymphocyte-mediated shortening of brush border microvilli with or without coinciding villous atrophy, disaccharidase deficiencies, small intestinal malabsorption, anion hypersecretion, and increased intestinal transit rates $[13,17 \bullet, 19 \bullet \bullet, 36 \bullet, 37,38 \bullet, 39,40,41 \bullet \bullet, 42]$. Impaired enterocyte cell cycle and proliferation, via the consumption of host arginine by the parasite, have also been suggested to contribute to pathogenesis [43]. The reduction in intestinal barrier function induced by giardiasis implicates disruptions of F-actin, zonula occludens 1 (ZO-1), claudin-1 and claudin- 4 , occludin, and $\alpha$-actinin, the latter being a component of the actomyosin ring that regulates paracellular flow $[19 \bullet \bullet, 38 \bullet, 41 \bullet \bullet, 44,45]$. Loss of epithelial barrier integrity is mediated by activation of epithelial myosin light chain kinase [46]. Disruptions of epithelial tight junctional proteins by Giardia are caspase-3-dependent, similarly to other enteric disorders [38•, 46, 47••, 48, 49]. However, recent findings also point to a direct role for cysteine proteases released by the parasite in the proteolytic disruption of epithelial villin, an important constituent of brush border microvilli $[50,51]$. Remodeling of intestinal epithelial villin has also been observed during late stages of $G$. duodenalis infection in vivo where it occurs via CD4+ and CD8+ immune responses [52•]. Interestingly, inhibition of parasite proteases does not seem to prevent degradation of the intestinal tight junction-associated protein ZO-1, consistent with the hypothesis that $G$. duodenalis induces epithelial pathophysiology via multiple pathways [49]. Overall, Giardia-induced diffuse shortening of brush border microvilli causes small intestinal malabsorption due to impaired absorption of water, glucose, and electrolytes. Anion hypersecretion may further contribute to the production of the resulting diarrhea $[19 \cdot \bullet$, 53-55]. Recent findings indicate that the pathogenic effects of Giardia may be further compounded by degradation of local mucins by the parasite [56], which may in turn contribute to the translocation of commensal bacteria through the epithelium $[45,56,57,58 \bullet]$. An isolated report indicates that giardiasis may be associated with increased mucus secretion, but the biological significance of this observation has yet to be determined [27]. Recent findings indicate that G. duodenalis may cause mucin depletion in goblet cells of the small intestine, as well as in the colon [56]. These phenomena warrant further investigation. While at least some of the pathogenic effects of Giardia are isolate-dependent, the identification of a Giardia "enterotoxin" has remained elusive. Various reports from Europe, Africa, South America, Asia, and Australia have attempted to correlate parasite genotype with symptoms. Some have suggested that assemblage B may cause more severe disease in humans [21•], but there are conflicting studies reporting otherwise, consistent with the fact that microbial, host, and environmental factors contribute to disease. These genotypic differences have raised the hitherto unsettled question of whether there are two different Giardia species [3••, 6, 9, 59, 60]. 


\section{Post-Infectious Complications in Giardiasis}

A variety of enteropathogens, including Giardia, have been associated with post-infectious complications, in the gut, as well as at extra-intestinal sites $[20 \bullet, 21 \bullet, 22 \bullet \bullet, 23,61 \bullet]$. A number of these microbes, including Campylobacter jejuni, the number one cause of bacterial enteritis worldwide, are also known to predispose susceptible individuals with inflammatory bowel disease (IBD) to inflammation flare-ups and exacerbation of disease [62]. Research is warranted to assess whether Giardia may also exacerbate symptoms in patients with IBD. Long-term and extra-intestinal consequences that have been reported for giardiasis include post-infectious irritable bowel syndrome, chronic fatigue syndrome, ocular pathologies, polyarthritis, allergies, and hypokalemic myopathy, as well as failure to thrive, stunting, and cognitive impairment in children [reviewed in $21 \bullet$ and $22 \bullet \bullet, 63 \bullet, 64 \bullet$ ].

In giardiasis and other enteric infections, severe diarrhea may lead to poor cognitive function caused by zinc and iron micronutrient deficiencies, as well as defects in the antioxidant system, which may all affect neuroplasticity [25•, 26, 65-67]. Indeed, studies conducted in Brazil and Peru observed that diarrheal disease occurring in the first 2 years of life negatively affects cognitive function, verbal fluency, and physical fitness and may lead to long-term growth faltering $[68,69]$. Post-infectious wasting and/or stunting often associates with general behavioral and developmental consequences that present as failure to thrive $[68,70,71]$. Other reports found that diarrhea during early childhood can impair visual-motor coordination, auditory short-term memory, information processing, and cortical cognitive function $[67,69]$. The exact biological bases of the post-infectious clinical sequelae due to Giardia, months and sometimes years after the parasite has been eliminated, remain unclear.

Cause-to-effect studies using models with human pathogens are needed to help characterize the mechanisms responsible for post-infectious complications following acute infection with enteropathogens. A recent study [45 unpublished] described a model of post-infectious irritable bowel syndrome in neonatal rats infected with $G$. duodenalis. Fifty days postinfection with G. duodenalis (Assemblage A or B), long after the parasite was cleared, rats developed visceral hypersensitivity to luminal balloon distension, activation of nociceptive signaling pathway characterized by increased c-fos expression, histological modifications (villus atrophy and crypt hyperplasia), and proliferation of intraepithelial lymphocytes and mucosal mast cells. G. duodenalis infection also disrupted intestinal barrier function, which in turn promoted the translocation of commensal bacteria, in association with the development of intestinal hypersensitivity. In that study, Giardiainduced bacterial translocation correlated with the degradation of the tight junctional proteins occludin and claudin-4. These findings clearly demonstrate that indeed, Giardia can cause post-infectious visceral hypersensitivity. Importantly, this report also shows that Giardia-induced visceral hypersensitivity may occur in the rectum, a site far remote from the site of parasitic colonization - consistent with Giardia-induced mucin depletion in the colon [56] - giving new impetus for research on the effects of giardiasis in the distal intestine.

\section{Microbial-Microbial Interactions in the Gut and Pathogenesis of Giardiasis}

Microbial-microbial interactions in the gut may play a key role in the disease outcome of giardiasis. Earlier findings have established that commensal microbiota may protect the host against Giardia [72]. Conversely, bacterial components of the microbiota from patients with symptomatic giardiasis appear to heighten $G$. intestinalis virulence in gnotobiotic mice, via unclear mechanisms [73]. Recent findings indicate that G. duodenalis may induce a relative expansion in the abundance of Firmicutes and the appearance of Proteobacteria groups in human gut microbiota [57 unpublished]. In that study, Giardia-modified human gut microbial communities also exhibited a significant capacity for epithelial translocation and intestinal invasion. Germ-free mice reconstituted with Giardia-treated human gut microbiota showed distinct increases in colonic pro-inflammatory mediators. These observations are consistent with the hypothesis that Giardia may cause representatives of the host commensal microbiota to become virulent. Indeed, various bacterial preparations, including human gut microbiota, induce lethal toxicity in Caenorhabditis elegans when administered concurrently with G. duodenalis [74••]. This may explain why abnormal gut permeability can persist post-infectiously in giardiasis [58, 74.•]. And when post-infectious complications persist for months, microscopic small intestinal inflammation may develop $[20 \bullet, 58 \bullet, 75]$. Together, these observations suggest that Giardia may increase the virulence of commensal microbiota bacteria during the acute phase of the infection. In turn, these altered microbiota will induce a host inflammatory response, which may be responsible, at least in part, for the long-term, post-infectious, complications seen in giardiasis. This topic represents an area of intense ongoing research and may help pave the way toward novel, "probiotic-like,"-based therapies.

\section{Immuno-Modulation by Giardia and Symptom Variability}

During the acute stage of the infection, Giardia trophozoite loads can exceed one million organisms per centimeter of gut, and yet, the intestinal mucosa of most Giardia-infected hosts does not exhibit any overt signs of inflammation, with the exception of a small increase in intra-epithelial lymphocytes 
and mucosal mast cell numbers [3••, 54, 76, 77]. Isolated reports have observed signs of microscopic duodenal inflammation in some patients infected with $G$. duodenalis assemblage $B[76,78]$. The reasons for this surprising attenuation of host intestinal inflammation remain unclear. Giardia infections are transmitted via ingestion of infectious cysts in contaminated food or water or directly via the fecal-oral route. This route of infection is shared by a broad variety of gastrointestinal pathogens, and as a result, Giardia co-infections are not uncommon [29・•]. The most commonly detected coenteropathogens include Vibrio cholera, rotavirus, norovirus, enteropathogenic E. coli, and Helicobacter pylori [79-81]. Giardia infections have also been reported to occur concurrently with Ascaris sp., Cryptosporidium sp., and Salmonella sp. [82-86]. Although most of these pathogens are known to promote inflammatory responses and induce diarrheal disease within their hosts, such co-infections are often asymptomatic [29••, 87]. Moreover, a recent study on Tanzanian children demonstrated that those infected with $G$. duodenalis had a reduced likelihood of developing diarrheal disease and fever as well as lower levels of serum C-reactive protein, a classic marker of inflammation, when compared to Giardia-negative children [25•]. These observations have prompted ongoing research into the immuno-modulating potential of Giardia.

Microarray analysis of jejunal tissues collected from G. duodenalis-infected calves has revealed decreased mRNA expression of several pro-inflammatory mediators and increased expression of anti-inflammatory factors [88]. Also, G. duodenalis may reduce host dendritic cell interleukin-12, partly via Giardia-induced arginine depletion [89•, 90]. Giardia arginine deiminase has also been shown to attenuate nitric oxide production from intestinal epithelial cells [91, 92•, 93]. Recent observations also revealed another immuno-modulatory effect by a parasite, in which assemblage A trophozoites attenuate the secretion of CXCL8 from human small intestinal mucosal biopsies administered with pro-inflammatory IL- $1 \beta$ or bacterial toxins and from human epithelial enterocytes administered with IL-1 $\beta$ or Salmonella typhimurium in vitro [29••, 87]. Further examination found that Giardia was also able to inhibit the production of a variety of pro-inflammatory mediators and chemokines in the mouse colon challenged with Clostridium difficile toxin $\mathrm{A} / \mathrm{B}$, as well as in inflamed human gut tissue biopsies from patients with Crohn's disease [29••]. This reduction of CXCL8 leads to decreased neutrophil chemotaxis and was the result of secreted $G$. duodenalis cathepsin B-like proteases that degraded CXCL8. The G. duodenalis genome contains genes for at least 23 cathepsin cysteine proteases, the majority of which have no described function [94, 95]. However, several G. duodenalis cathepsin proteases are upregulated upon exposure to intestinal epithelial cells $[87,96]$. Even though cathepsin protease assays suggested that assemblage B $G$. duodenalis trophozoites secrete cysteine proteases with similar activity, these failed to degrade CXCL8, indicative of an isolate-specific effect
$[28 \bullet, 87]$. These findings demonstrate that assemblage A G. duodenalis trophozoites possess immunomodulatory factors that may inhibit pro-inflammatory intestinal responses in infected tissues. It is well known that neutrophils induce intestinal epithelial anion hypersecretion and, consequently, water loss, and diarrhea [97, 98]. Hence, as neutrophil accumulation contributes to the development of diarrheal disease, the local release of direct immunomodulatory Giardia cathepsins may help explain the lower inflammation scores and reduced incidence of diarrhea in hosts co-infected with $G$. duodenalis and enteropathogens that cause diarrhea via intestinal inflammation. In host populations where co-infections with pro-inflammatory enteropathogens are less common, Giardia on its own is a cause of diarrheal disease. Whether and how Giardia's immunomodulating effects may also modify the intestinal environment to make it more favorable for colonization by other pathogens requires further investigation. More research is also needed to examine the structure and function of $G$. duodenalis cathepsin B-like proteases to determine if these factors exhibit unique substrate specificities and whether other proteases participate in the degradation of CXCL8 and/or other immune mediators.

\section{Virulence Factors and Disease Pathogenesis}

A true Giardia enterotoxin has yet to be identified, and attempts to ascribe symptom variability to Giardia genotypes have remained inconclusive. Proteomic analysis revealed that the breadth of repertoire of Giardia variant surface proteins is isolate-dependent [99•]. While exposure to epithelial cells does result in significant changes in Giardia trophozoite gene expression and the release of several Giardia-produced metabolic enzymes [91], the effects of these parasite factors on the host remain largely unknown.

A few virulence factors have been suggested on the basis of their targeted effects $[3 \bullet \bullet, 16]$. For example, ventral adhesive disc proteins and surface lectins ensure appropriate attachment to enterocytes of the upper small intestine, while the four pairs of flagella allow for movement, and variant surface proteins help evade host IgA-directed clearance [3••, 93, 100]. Variant surface protein expression may also confer zoonotic infectivity to Giardia isolates [101]. The arginine deiminase produced by the parasite deprives intestinal epithelial cells of arginine, thereby impairing intestinal epithelial proliferation and nitric oxide production [43, 91, 92•]. Alpha-2 giardin appears to be an assemblage A-specific protein [102], but its role in hostparasite interactions remains obscure. An unknown 58-kDa product released by Giardia trophozoites has been reported to induce anion hypersecretion and intestinal fluid accumulation by activating signal transduction pathways in host enterocytes [103]. However, parasite products directly involved in the pathogenesis of giardiasis remain largely unknown. 


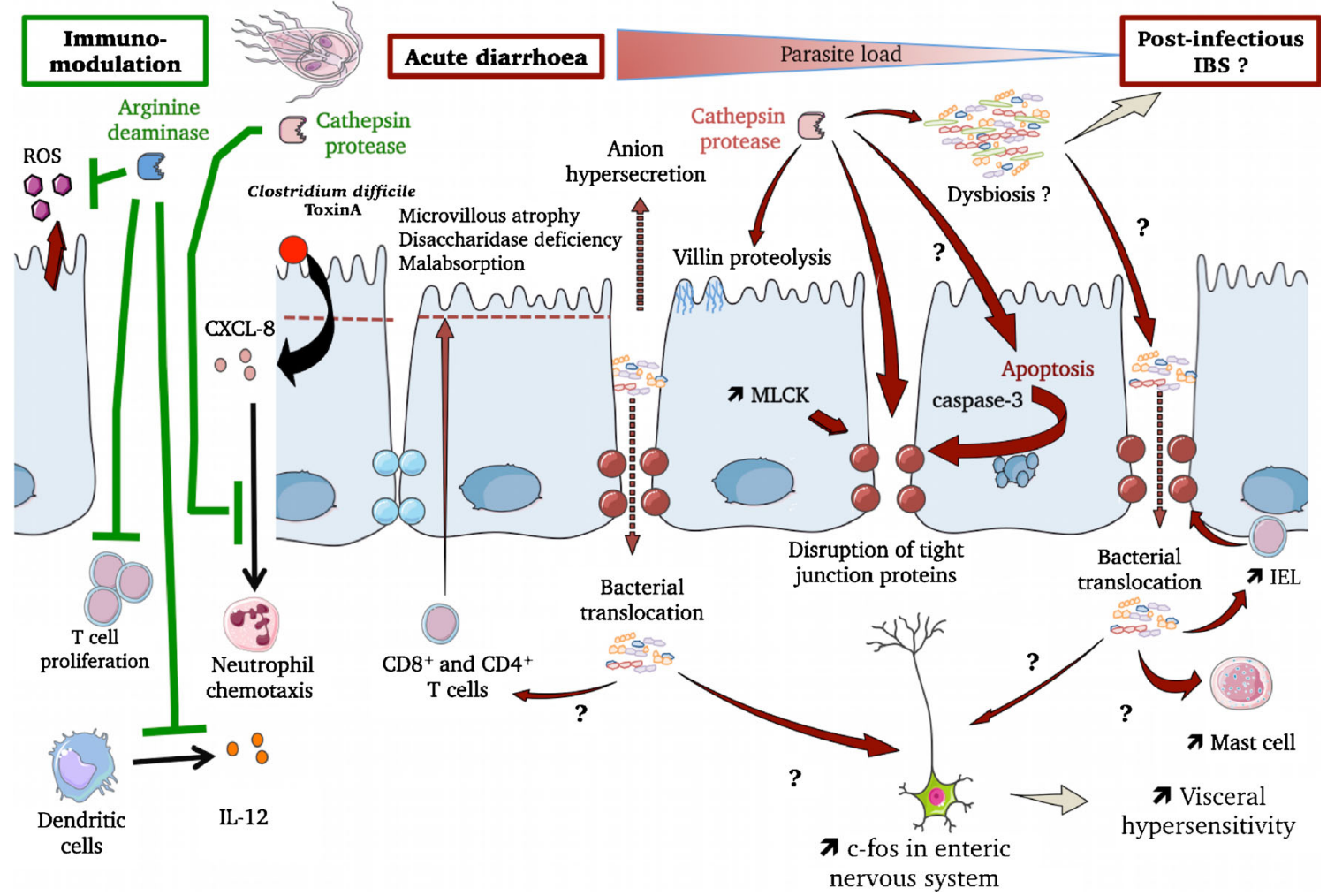

Fig. 1 Mucosal response to Giardia duodenalis infection. The figure illustrates mechanisms whereby the parasite causes immuno-modulation and physiopathology in the host

Cathepsin-like cysteine proteases are key components of the pathogenesis of several protozoan parasitic disorders, and the Giardia genome contains genes for 23 of those proteases $[94,95,104,105]$. Cathepsin cysteine proteases contain an active site cysteine and histidine residue. In addition, these proteases are further subdivided into cathepsin B or cathepsin L superfamilies (reviewed in [104, 106]). Cysteine protease activity has been reported in $G$. duodenalis cultures [51, 107]. However, the functions of these proteases are mostly unknown, and their role in giardiasis remains obscure. Thus far, it has been established that cathepsin-like cysteine proteases are required for trophozoite encystation and excystation [94]. Adding to recent reports that G. duodenalis cathepsin Blike cysteine proteases degrade CXCL8 and attenuate neutrophil chemotaxis [29••, 87], recent findings also suggest a role for these proteases in the disruption of enterocytic cytoskeletal villin. More research is needed to characterize virulence factors in $G$. duodenalis genotypes and how these may, in turn, induce pathophysiological responses in the host intestine.

\section{Conclusions}

G. duodenalis is a cosmopolitan diarrheagenic parasite of humans and a variety of animal species. Its significant impact on human health and the livestock industry has warranted its inclusion in the World Health Organization's (WHO) Neglected Diseases Initiative. Recent observations have established that the parasite can cause post-infectious visceral hypersensitivity, adding G. duodenalis to the list of enteropathogens known to be responsible for post-infectious irritable bowel syndrome. As summarized in Fig. 1, the mechanisms responsible for pathophysiology in giardiasis include both parasite and host immune factors, as well as Giardiainduced microbiota disruptions that may directly contribute to the post-infectious gastrointestinal disorder associated with the infection. Giardia induces enterocyte apoptosis and disrupts the epithelial barrier in myosin-light chain kinasedependent manner. In turn, CD8+ lymphocyte-dependent microvillus shortening causes maldigestion and malabsorption. Compounding these effects, Giardia may also increase chloride secretion and intestinal transit, all of which further contribute to diarrhea. Intriguingly, in developing countries, where co-infections with other enteropathogens are not uncommon, the infection may protect against pediatric diarrhea. Further research needs to determine whether symptom variability can be ascribed to the immuno-modulating capacity of Giardia cathepsin-B-like proteases. The effects of heterologous infections by different Giardia genotypes also need to be investigated. To date, little is known of the virulence factors responsible for disease. The recent demonstration that a G. duodenalis surface cathepsin B-like cysteine protease 
may cleave epithelial cytoskeletal villin lays the foundations toward more research into the role of Giardia proteases in pathogenesis. Together, the findings reported to date illustrate that Giardia offers a powerful model system to investigate both the mechanisms of acute infectious diarrhea, as well as the mechanisms responsible for the post-infectious sequelae of parasitic, bacterial, and viral enteritis. As such, this research will help develop a rational basis for the development of new therapeutics.

Acknowledgments Components of the findings discussed in this article have been generated with the financial support of research grants from the Natural Sciences and Engineering Research Council of Canada. JPM is funded through Fellowships from The Alberta Innovates Health Solutions, the Canadian Institutes of Health Research, and the Canadian Association of Gastroenterologists, as well as by institutional support through an Eyes High and a Killam Fellowship. Materials from Servier Medical Art were adapted for the preparation of Fig. 1 (Creative Common license CC-BY).

\section{Compliance with Ethics Guidelines}

Conflict of Interest Andre G. Buret, Christina B. Amat, Anna Manko, Jennifer K. Beatty, Marie C.M. Halliez, Amol Bhargava, Jean-Paul Motta, and James A. Cotton declare that they have no conflict of interest.

Human and Animal Rights and Informed Consent Some of the studies referenced in this review article used human and animal subjects. All studies by the present authors have been performed in compliance with the Human Review Ethics Board, and human subjects provided full consent. All studies were compliant with the Animal Care Review committees at the University of Calgary and with the regulations of Canadian Council on Animal Care.

\section{References}

Papers of particular interest, published recently, have been highlighted as:

- Of importance

•. Of major importance

1. Savioli L, Smith H, Thompson A. Giardia and Cryptosporidium join the 'neglected diseases initiative'. Trends Parasitol. 2006;22(5):203-8. Article that included giardiasis in the World Health Organization's (WHO) Neglected Diseases Initiative.

2. WHO guidelines for drinking water quality launched in 2004 . http://www.who.int/water_sanitation_health/dwq/gdwq3/en/

3.• Ankarlev J, Jerlstrom-Hultqvist J, Ringqvist E, Troell K, Svard SG. Behind the smile: cell biology and disease mechanisms of Giardia species. Nat Rev Microbiol. 2010;8:413-22. Detailed and up-to-date review on Giardia and giardiasis.

4. Ross AG, Olds GR, Cripps AW, Farrar JJ, McManus DP. Enteropathogens and chronic illness in returning travelers. $\mathrm{N}$ Engl J Med. 2013;368:1817-25.

5. Lasek-Nesselquist E, Welch DM, Sogin ML. The identification of a new Giardia duodenalis assemblage in marine vertebrates and a preliminary analysis of G. duodenalis population biology in marine systems. Int J Parasitol. 2010;40:1063-74.
6. Franzen O, Jerlstrom-Hultqvist J, Castro E, Sherwood E, Ankarklev J, et al. Draft genome sequencing of giardia intestinalis assemblage B isolate GS: is human giardiasis caused by two different species? PLoS Pathog. 2013;5:e1000560.

7. Feng Y, Xiao L. Zoonotic potential and molecular epidemiology of Giardia species and giardiasis. Clin Microbiol Rev. 2011;24(1): $110-40$.

8. Ryan U, Caccio S. Zoonotic potential of Giardia. Int J Parasitol. 2013;43(12-13):943-56.

9. Thompson RC, Monis P. Giardia-from genome to proteome. Adv Parasitol. 2012;78:57-95.

10. Dixon B, Parringotn L, Cook A, Pintar K, Pollari F, Kelton D, et al. The potential for zoonotic transmission of Giardia duodenalis and Cryptosporidium spp. From beef and dairy cattle in Ontario, Canada. Vet Parasitol. 2011;175(1-2):20-6.

11. Buret A, Den Hollander N, Wallis PM, Befus D, Olson ME. Zoonotic potential of giardiasis in domestic ruminants. J Infect Dis. 1990;162:231-7.

12. Geurden T, Vanderstichel R, Pohle H, Ehsan A, Von SamsonHimmelstjerna G, Morgan E, et al. A multicentre prevalence study in Europe on Giardia duodenalis in calves, with molecular identification and risk factor analysis. Vet Parasitol. 2012;190:383-90.

13. O'Handley R, Buret A, Mcallister TA, Jelinsky M, Olson ME. Giardiasis in dairy calves: effects of fenbendazole treatment on intestinal structure and function. Int J Parasitol. 2001;31:73-9.

14. Olson ME, Mcallister TA, Deselliers L, Morck DW, Cheng KJ, Buret A, et al. The effects of giardiasis on production in a ruminant model. Am J Vet Res. 1995;56(11):1470-4.

15. Geurden T, Vandenhoutte E, Pohle H, Casaert S, De Wilde N, Vercruysse $\mathrm{J}$, et al. The effect of a fenbendazole treatment on cyst excretion and weight gain in calves experimentally infected with Giardia duodenalis. Vet Parasitol. 2010;169:18-23.

16. Cotton J, Beatty J, Buret AG. Host-parasite interactions in giardiasis. Int J Parasitol. 2011;41:925-33.

17. Buret AG, Hardin JA, Olson ME, Gall DG. Pathophysiology of small intestinal malabsorption in gerbils infected with Giardia lamblia. Gastroenterology. 1992;103(2):506-13. First demonstration that Giardia causes malabsorptive diarrhea by diffuse brush border microvillous shortening.

18. De Filippo C, Cavalieri D, Di Paola M, et al. Impact of diet in shaping gut microbiota revealed by a comparative study in children from Europe and rural Africa. Proc Natl Acad Sci U S A. 2010;107:14691-6.

19.•• Troeger H, Eppel HJ, Schneider T, Wahnschaffe U, Ulrich R, Burchard GD, et al. Effect of chronic Giardia lamblia infection on epithelial transport and barrier function in human duodenum. Gut. 2007;56:328-35. First human study demonstrating the role of enterocyte apoptosis, loss of brush border surface area, and malabsorption in the pathophysiology of diarrhea during giardiasis.

20. Hanevik K, Dizdar V, Langeland N, Hausken T. Development of functional gastrointestinal disorders after Giardia lamblia infection. BMC Gastroenterol. 2009;9:27-31. Demonstration that giardiasis causes post-infectious functional disorders of the gut in human subjects.

21. Robertson LJ, Hanevik K, Escobedo AA, Mørch K, Langeland N. Giardiasis why do the symptoms sometimes never stop? Trends Parasitol. 2010;26(2):75-82. Detailed review on the postinfectious intestinal complications of giardiasis in humans.

22.• Halliez MCM, Buret AG. Extra-intestinal and long term consequences of Giardia duodenalis infections. World J Gastroenterol. 2013;19(47):8974-85. Detailed and up-to-date review on the extra-intestinal and post-infectious complications of giardiasis.

23. Buret AG, Reti K. Acute enteric infections alter commensal microbiota: new mechanisms in post-infectious intestinal inflammatory disorders. In: Heidt PJ, Lang D, Riddle MS, Walker RI, Rusch 
V. editors. Persisting consequences of intestinal infections. Old Herborn University Monograph, OHUS; 2014. pp. 87-106.

24. Beatty JK, Bhargava A, Buret AG. Post-infectious irritable bowel syndrome: mechanistic insights into chronic disturbances following enteric infection. World J Gastroenterol. 2014;20(14):397685.

25. Veenemans J, Mank T, Ottenhof M, Baidjoe A, Mbugi EV, Demir AY, et al. Protection against diarrhea associated with Giardia intestinalis is lost with multi-nutrient supplementation: a study in Tanzanian children. PLoS Neg1 Trop Dis. 2011;5:e1158. Demonstration that in endemic areas of the World, giardiasis may protect against diarrheal disease.

26. Simsek Z, Zeyrek FY, Kurcer MA. Effect of Giardia infection on growth and psychomotor development of children aged $0-5$ years. J Trop Pediatr. 2004;50(2):90-3.

27. Lengerich EJ, Addiss DG, Juranek DD. Severe giardiasis in the United States. Clin Infect Dis. 1994;18:760-3.

28. Bartelt LA, Roche J, Kolling G, Bolick D, Noronha F, Naylor C, et al. Persistent Giardia lamblia impairs growth in a murine malnutrition model. J Clin Invest. 2013;123(6):2672-84. Demonstration of the post-infectious effects of giardiasis on growth in a murine malnutrition model.

29.• Cotton J, Motta JP, Schenk LP, Hirota SA, Beck PL, Buret AG. Giardia duodenalis infection reduces granulocyte infiltration in an in vivo model of bacterial toxin-induced colitis and attenuates inflammation in human intestinal tissue. PLoS ONE. 2014; e109087. doi: 10.1371/journal.pone.0109087. First demonstration that Giardia attenuates intestinal inflammation caused by bacterial toxins or chronic inflammatory disease in human tissues.

30. Koh WH, Geurden T, Paget T, O'Handley R, Steuart RF, Thompson RCA. Buret AG Giardia duodenalis assemblagespecific induction of apoptosis and tight junctional disruption in human intestinal epithelial cells: effects of mixed infections. J Parasitol. 2013;99(2):353-8.

31. Roxstrom-Lindquist K, Palm D, Reiner D, Ringqvist E, Svärd SG. Giardia immunity — an update. Trends Parasitol. 2006;22:26-31.

32. Centre for disease control and prevention, Report, March 14, 2012.

33. Yoder JS, Harral C, Beach MJ, Centers for Disease Prevention. Giardiasis surveillance-United States, 2006-2008. MMWR Surveill Summ. 2010;59:15-25.

34. Jensen LA, Marlin JW, Dyck DD, Laubach HE. Prevalence of multi-gastrointestinal infections with helminth, protozoan and Campylobacter spp. in Guatemalan children. J Infect Dev Countries. 2009;3(3):229-34.

35. Nash TE, Herrington DA, Losonsky GA, Levine MM. Experimental human infections with Giardia lamblia. J Infect Dis. 1987;156:974-84.

36. Scott KG, Yu LC, Buret AG. Role of $\mathrm{CD}^{+}$and $\mathrm{CD} 4^{+} \mathrm{T}$ lymphocytes in jejunal mucosal injury during murine giardiasis. Infect Immun. 2004;72(6):3536-42. First demonstration that host CD8+ T lymphocytes are responsible for the diffuse shortening of gut epithelial brush microvilli and resulting disaccharidase deficiencies in giardiasis.

37. Scott KG, Logan MR, Klamer GM, Teoh DA, Buret AG. Effects of Giardia muris infection on jejunal architecture, brush border ultrastructure, disaccharidases and interleukin-6: the role of T-lymphocytes. Infect Immun. 2010;68(6):3412-8.

38. Chin AC, Teoh DA, Scott KG, Meddings JB, Macnaughton WK, Buret AG. Strain-dependent induction of enterocytes apoptosis by Giardia lamblia disrupts epithelial barrier function in a caspase-3dependent manner. Infect Immun. 2002;70(7):3673-80. First demonstration that Giardia disrupts epithelial tight junctional proteins via induction of enterocyte apoptosis.
39. Panaro MA, Cianciulli A, Mitolo V, Acquafreda A, Brandonisio O, Cavallo P. Caspase-dependent apoptosis of the HCT-8 epithelial cell line induced by the parasite Giardia intestinalis. FEMS Immunol Med Microbiol. 2007;51(2):302-9.

40. Koot BGP, ten Kate FJW, Juffrie M, Rosalina I, Taminiau JJAM, Benninga MA. Does Giardia lamblia cause villous atrophy in children?: A retrospective cohort study of the histological abnormalities in giardiasis. J Pediatr Gastroenterol Nutr. 2009;49:304-8.

41.• Scott KG, Meddings JB, Kirk DR, Lees-Miller SP, Buret AG. Intestinal infection with Giardia spp. reduces epithelial barrier function in a myosin light chain-kinase dependent fashion. Gastroenterology. 2002;123:1179-90. First demonstration of the role of enterocyte myosin light chain-kinase in the loss of intestinal barrier function caused by giardiasis in vivo.

42. Deselliers LP, Tan DT, Scott RB, Olson ME. Effects of Giardia lamblia on gastrointestinal transit and contractility in Mongolian gerbils. Dig Dis Sci. 1997;42(2):2411-9.

43. Stadelmann B, Hanevik K, Andersson MK, Bruserud O, Svard SG. The role of arginine and arginine-metabolizing enzymes during Giardia-host cell interactions in vitro. BMC Microbiol. 2013;13:256

44. Teoh DA, Kamieniecki D, Pang G, Buret AG. Giardia lamblia rearranges $\mathrm{F}$-actin and alpha-actinin in human colonic and duodenal monolayers and reduces transepithelial electrical resistance. J Parasitol. 2000;86:800-6.

45. Halliez MCM, LeGoff L, Francois A, Colasse E, Gargala G, Villena I, et al. Novel insights in post-infectious irritable bowel syndrome in experimental giardiasis. FASEB J. 2014;28(1): 650.65 .

46. Chin AC, Flynn AN, Fedwick JP, Buret AG. The role of caspase-3 in lipopolysaccharide-mediated disruption of epithelial tight junctions. Can J Physiol Pharmacol. 2006;84(10):1043-50.

47.• Chin AC, Vergnolle N, Macnaughton WK, Wallace JL, Hollenberg MD, Buret AG. Proteinase-activated receptor-1 activation induces epithelial apoptosis and increases intestinal permeability. Proc Natl Acad Sci USA. 2013;100:11104-9. First demonstration that activation of epithelial proteinase-activated receptors may disrupt intestinal barrier function by inducing enterocyte apoptosis.

48. Buret AG, Bhargava A. Modulatory mechanisms of enterocyte apoptosis by viral, bacterial and parasitic pathogen. Crit Rev Microbiol. 2013. doi:10.3109/1040841X.2012.746952.

49. O'Hara JR, Buret AG. Mechanisms of intestinal tight junctional disruption during infection. Front Biosci. 2008;13:7008-21.

50. Bhargava A, Cotton JA, Yates RM, Buret AG. Giardia duodenalis cysteine cathepsin proteases and their role in intestinal disease. FASEB J. 2013;27(1):647.7.

51. Rodriguez-Fuentes GB, Cedillo-Rivera R, Fonseca-Linan R, Arguello-Garcia R, Munoz O, Ortega-Pierres G, et al. Giardia duodenalis: analysis of secreted proteases upon trophozoiteepithelial cell interaction in vitro. Mem Inst Oswaldo Cruz. 2006;101(771):693-6.

52. Solaymani-Mohammadi S, Singer SM. Regulation of intestinal epithelial cell cytoskeletal remodeling by cellular immunity following gut infection. Mucosal Immunol. 2013;6:369-78. Review of the mechanisms whereby cellular immunity may alter enterocytic cytoskeletal proteins following gut infection.

53. Gorowara S, Ganguly NK, Mahajan RC, Walia BN. Study on the mechanism of Giardia lamblia induced diarrhoea in mice. Biochim Biophys Acta. 1992;1138:122-6.

54. Cevallos A, Carnaby S, James M, Farthing JG. Small intestinal injury in a neonatal rat model of giardiasis is strain dependent. Gastroenterology. 1995;109:766-73.

55. Baldi F, Bianco MA, Nardone G, Pilotto A, Zamparo E. Focus on acute diarrhoeal disease. World J Gastroenterol. 2009;15:3341-8. 
56. Amat C, Motta JP, Bhargava A, Chadee K, Buret AG. Giardia duodenalis depletes goblet cell mucins and degrades MUC2, facilitating bacterial translocation. FASEB J. 2015;29(1):507.1.

57. Beatty JK, Akierman SV, Rioux KP, Beck PL, McKnight W, Feener T, et al. Gut microbiota biofilm disruptions by Giardia: pathology in human enterocytes and germ-free mice. FASEB J. 2013;27(1):131.1.

58. Chen TL, Chen H, Wu HW, Lee TC, Lu YZ, Wu LL, et al. Persistent gut barrier damage and commensal bacterial influx after eradication of Giardia infection in mice. Gut Pathog. 2013;26(5): $1-12$. Demonstration that giardiasis may cause a postinfectious loss of barrier function and translocation of commensal bacteria in a model in vivo.

59. Xu F, Jerlstrom-Hultqvist J, Andersson JO. Genome-wide analyses of recombination suggest that Giardia intestinalis assemblages represent different species. Mol Biol Evol. 2012;29(838):2895-8.

60. Monis PT, Caccio SM. Thompson RC variation in Giardia: towards a taxonomic revision of the genus. Trends Parasitol. 2009;25:93-100.

61. Hanevik K, Wensaas KA, Rørtveit G, Eide GE, Mørch K, Langeland N. Irritable bowel syndrome and chronic fatigue 6 years after Giardia infection: a controlled prospective cohort study. Clin Infect Dis. 2014;59:1394-400. Controlled prospective cohort study of the giardiasis outbreak in Bergen showing that giardiasis is associated with post-infectious IBS and chronic fatigue.

62. Kalischuk LD, Buret AG. A role for Campylobacter jejuniinduced enteritis in inflammatory bowel disease? Am J Physiol Gastrointest Liver Physiol. 2010;298(1):G1-9.

63. Bartelt LA, Roche J, Kolling G, Bolick D, Noronha F, Naylor C, et al. Persistent $\mathrm{G}$. lamblia impairs growth in a murine malnutrition model. J Clin Invest. 2013;123:2672-84. Demonstration that giardiasis can retard growth in infected mice.

64.•- Bartelt LA MAL-ED. Network Investigators. The MAL-ED study: a multinational and multidisciplinary approach to understand the relationship between enteric pathogens, malnutrition, gut physiology, physical growth, cognitive development, and immune responses in infants and children up to 2 years of age in resource-poor environments. Clin Infect Dis. 2014;59(4):S193206. Study demonstrating that enteric pathogens, including Giardia, cause malnutrition, impair growth, and slow cognitive development in infants and children up to 2 years of age in developing countries of the World.

65. Koruk I, Simsek Z, Tekin Koruk S, Doni N, Gürses G. Intestinal parasites, nutritional status and psychomotor development delay in migratory farm worker's children. Child Care Health Dev. 2010;36(6):888-94.

66. Botero-Garcés JH, García-Montoya GM, Grisales-Patiño D. Giardia intestinalis and nutritional status in children participating in the complementary nutrition program, Antioquia, Columbia, May to October 2006. Revista do Institudo do Medicina Tropical do São Paulo. 2009;51(3):155-62.

67. Ajjampur SSR, Koshy B, Venkataramani M, Sarkar R, Joseph AA, Jacob KS, et al. Effect of cryptosporidial and giardial diarrhea on social maturity, intelligence and physical growth in children in a semi-urban slum in south India. Ann Trop Paediatr. 2011;31: 205-12.

68. Berkman DS, Lescano AG, Gilman RH, Lopez SL, Black MM. Effects of stunting, diarrhoeal disease, and parasitic infection during infancy on cognition in late childhood: a follow-up study. Lancet. 2002;359(9306):564-71.

69. Guerrant DI, Moore SR, Lima AAM, Patrick PD, Schorling JB, Guerrant RL. Association of early childhood diarrhea and cryptosporidiosis with impaired fitness and cognitive function fourseven years later in a poor urban community in northeast Brazil. Am J Trop Med Hyg. 1999;61(5):707-13.
70. Ettehad GH, Daryani A, Nemati A. Effect of Giardia infection on nutritional status in primary schoolchildren, in northwest Iran. Pak J Biol Sci. 2010;13(5):229-34.

71. Bergman P, Graham J. An approach to 'failure to thrive'. Aust Fam Physician. 2005;34(9):725-9.

72. Singer SM, Nash TE. The role of normal flora in Giardia lamblia infections in mice. J Infect Dis. 2000;181(4):1510-2.

73. Torres MF, Uetanabaro APT, Costa AF, Alves CA, Farias LM, Bambirra EA, et al. Influence of bacteria from the duodenal microbiota of patients with symptomatic giardiasis on the pathogenicity of Giardia duodenalis in gnotoxenic mice. J Med Microbiol. 2000;49(3):209-15.

74.• Gerbaba T, Gupta P, Rioux K, Hansen D, Buret AG. Giardia duodenalis-induced alterations of commensal bacteria are toxic to Caenorhabditis elegans: a new model to study microbial-microbial interactions in the gut. Am J Physiol Gastrointest Liver Physiol. 2015;308(6):G550-G61. Demonstration that Giardia makes human microbiota toxic in a novel $\mathrm{C}$. elegans model.

75. Mørch K, Hanevik K, Rortveit G, Wensaas KA, Eide GE, Hausken T, et al. Severity of Giardia infection associated with post-infectious fatigue and abdominal symptoms two years after. BMC Infect Dis. 2009;9:206-14.

76. Oberhuber G, Kastner N, Stolte M. Giardiasis: a histologic analysis of 567 cases. Scand J Gastroenterol. 1997;32:48-51.

77. Hardin JA, Buret A, Olson ME, Kimm M, Gall DG. Mast cell hyperplasia and increased macromolecular uptake in an animal model of giardiasis. J Parasitol. 1997;83(5):908-12.

78. Hanevik K, Hausken T, Morken MH, Strand EA, Morch K, et al. Persisting symptoms and duodenal inflammation related to Giardia duodenalis infection. J Infect. 2007;55:524-30.

79. Mukherjee AK, Chowdhury P, Rajendran K, Nozaki T, Ganguly S. Association between Giardia duodenalis and coinfection with other diarrhea-causing pathogens in India. Biomed Res Int. 2014;2014:786480.

80. Becker-Dreps S, Bucardo F, Vilchez S, Zambrana LE, Liu L, Weber DJ, et al. Etiology of childhood diarrhea after rotavirus vaccine introduction: a prospective, population-based study in Nicaragua. Pediatr Infect Dis J. 2014;33:1156-63.

81. Ankarklev J, Hestvik E, Lebbad M, Lindh J, Kaddu-Mulindwa $\mathrm{DH}$, et al. Common coinfections of Giardia intestinalis and Helicobacter pylori in nonsymptomatic Ugandan children. PLoS Negl Trop Dis. 2012;6:e1780.

82. Hagel I, Cabrera M, Puccio F, Santaella C, Buvat E, et al. Coinfection with Ascaris lumbricoides modulates protective immune responses against Giardia duodenalis in school Venezuelan rural children. Acta Trop. 2011;117:189-95.

83. Wang L, Xiao L, Duan L, Ye J, Guo Y, et al. Concurrent infections of Giardia duodenalis, Enterocytozoon bieneusi, and Clostridium difficile in children during a cryptosporidiosis outbreak in a pediatric hospital in China. PLoS Negl Trop Dis. 2013;7:e2437.

84. Oberhelman RA, Flores-Abuxapqui J, Suarez-Hoil G, Puc-Franco $\mathrm{M}$, Heredia-Navarrete $\mathrm{M}$, et al. Asymptomatic salmonellosis among children in daycare centers in Merida, Yucatan, Mexico. Pediatr Infect Dis J. 2011;20:792-7.

85. Bilenko N, Levy A, Dagan R, Deckelbaum RJ, El-On Y, et al. Does coinfection with Giardia lamblia modulate the clinical characteristics of enteric infections in young children? Eur J Epidemiol. 2004;19:877-83.

86. Bhavnani D, Goldstick JE, Cevallos W, Trueba G, Eisenberg JN. Synergistic effects between rotavirus and coinfecting pathogens on diarrheal disease: evidence from a community-based study in northwestern Ecuador. Am J Epidemiol. 2012;176:387-95.

87. Cotton J, Bhargava A, Ferraz J, Yates R, Beck PL, Buret AG. Giardia duodenalis cathepsin B proteases degrade intestinal epithelial interleukin- 8 and attenuate interleukin-8-induced neutrophil chemotaxis. Infect Immun. 2014;82(7):2772-87. 
88. Dreesen L, Rinaldi M, Chiers K, Li R, Geurden T, et al. Microarray analysis of the intestinal host response in Giardia duodenalis assemblage E infected calves. PLoS One. 2012;7(7): e40985. doi:10.1371/journal.pone.0040985.

89. Kamda JD, Singer SM. Phosphoinositide 3-kinase-dependent inhibition of dendritic cell interleukin-12 production by Giardia lamblia. Infect Immun. 2009;77:685-93. Demonstration that Giardia may have direct immuno-modulating effects on host dendritic cells.

90. Banik S, Renner Viveros P, Seeber F, Klotz C, Ignatius R, et al. Giardia duodenalis arginine deiminase modulates the phenotype and cytokine secretion of human dendritic cells by depletion of arginine and formation of ammonia. Infect Immun. 2013;81: 2309-17.

91. Ringqvist E, Palm JE, Skarin H, Hehl AB, Weiland M, et al. Release of metabolic enzymes by Giardia in response to interaction with intestinal epithelial cells. Mol Biochem Parasitol. 2008;159:85-91.

92. Eckmann L, Laurent F, Langford TD, Hetsko ML, Smith JR, et al. Nitric oxide production by human intestinal epithelial cells and competition for arginine as potential determinants of host defense against the lumen-dwelling pathogen Giardia lamblia. J Immunol. 2000;164:1478-87. Demonstration that Giardia may deplete host enterocytes of arginine and inhibit epithelial nitric oxide production.

93. Adam RD. Biology of Giardia lamblia. Clin Microbiol Rev. 2001;14:447-75.

94. DuBois KN, Abodeely M, Sakanari J, Craik CS, Lee M, et al. Identification of the major cysteine protease of Giardia and its role in encystation. J Biol Chem. 2008;283:18024-31.

95. Aurrecoechea C, Brestelli J, Brunk BP, Carlton JM, Dommer J, et al. GiardiaDB and TrichDB: integrated genomic resources for the eukaryotic protist pathogens Giardia lamblia and Trichomonas vaginalis. Nucleic Acids Res. 2009;37:D526-30.

96. Ma'ayeh SY. Brook-Carter PT Representational difference analysis identifies specific genes in the interaction of Giardia duodenalis with the murine intestinal epithelial cell line, IEC-6. Int J Parasitol. 2012;42:501-9.
97. Weissmuller T, Campbell EL, Rosenberger P, Scully M, Beck PL, et al. PMNs facilitate translocation of platelets across human and mouse epithelium and together alter fluid homeostasis via epithelial cell-expressed ecto-NTPDases. J Clin Invest. 2008;118:368292.

98. Madara JL, Parkos C, Colgan S, MacLeod RJ, Nash S, et al. Clsecretion in a model intestinal epithelium induced by a neutrophilderived secretagogue. J Clin Invest. 1992;89:1938-44.

99. Emery SJ, van Sluyter S, Haynes PA. Proteomic analysis in Giardia duodenalis yields insights into strain virulence and antigenic variation. Proteomics. 2014;14:2523-34. Novel insights into possible relationships between Giardia proteomics and strain virulence and antigenic variation.

100. Aggarwal A, Merritt Jr JW, Nash TE. Cysteine-rich variant surface proteins of Giardia lamblia. Mol Biochem Parasitol. 1989;32:39 47.

101. Singer SM, Elmendorf HG, Conrad JT, Nash TW. Biological selection of variant-specific surface proteins in Giardia lamblia. J Infect Dis. 2001;183:119-24.

102. Steuart RF, O'Handley R, Lipscombe RJ, Lock RA, Thompson $\mathrm{RC}$. Alpha 2 giardin is an assemblage a-specific protein of human infective Giardia duodenalis. Parasitology. 2008;135:1621-7.

103. Shant J, Ghosh S, Bhattacharyya S, Ganguly NK, Majumdar S. Mode of action of a potentially important excretory-secretory product from Giardia lamblia in mice enterocytes. Parasitology. 2005;131:57-69.

104. McKerrow JH, Caffrey C, Kelly B, Loke P, Sajid M. Proteases in parasitic diseases. Annu Rev Pathol. 2006;1:497-536.

105. Kissoon-Singh V, Mortimer L, Chadee K. Entamoeba histolytica cathepsin-like enzymes: interactions with the host gut. Adv Exp Med Biol. 2011;712:62-83.

106. Turk V, Stoka V, Vasiljeva O, Renko M, Sun T, Turk B, et al. Cysteine cathepsins: from structure, function and regulation to new frontiers. Biochim Biophys Acta. 1824;2012:68-88.

107. Coradi ST, Guimaraes S. Giardia duodenalis: protein substrates degradation by trophozoite proteases. Parasitol Res. 2006;99: $131-6$. 